\title{
New Experimental Procedure for the Analysis of Micro-Scale Surface Damage at High Temperature
}

\author{
M.F. Kiu ${ }^{1}$ - C. Pinna ${ }^{1}$ (D) D.C.J. Farrugia ${ }^{2}$
}

Received: 4 November 2015 / Accepted: 24 February 2016 / Published online: 9 March 2016

(C) The Author(s) 2016. This article is published with open access at Springerlink.com

\begin{abstract}
A new experimental procedure has been developed to study micro-crack formation at the surface of compression specimens deformed at high temperature under thermomechanical conditions representative of hot forming operations for steels. Damage formation in a Fe-30wt\%Ni alloy has been studied in relation to strain distributions measured at the scale of the microstructure using a microgrid technique. $20 \mu \mathrm{m}$-pitch microgrids have been deposited at the surface of a tapered specimen designed to generate critical levels of stress triaxiality representative to those leading to edge cracking in hot rolled steel products. The specimen was deformed using a revised plane strain compression test carried out under vacuum in a Gleeble machine at $1000{ }^{\circ} \mathrm{C}$. The grid distortion after the test has then been analysed to produce strain distribution maps which show local strain values ranging from 0 to $75 \%$ for an applied compression of $25 \%$. Strain localisation has been commonly observed along grain boundaries where damage is initiated at high temperature. Results therefore provide new insight into the early stages of damage formation at the surface of hot rolled products.
\end{abstract}

C. Pinna

c.pinna@sheffield.ac.uk

M. F. Kiu

mep10mfk@sheffield.ac.uk

D. C. J. Farrugia

didier.farrugia@tatasteel.com

1 Department of Mechanical Engineering, The University of Sheffield, Mappin Street, Sheffield S1 3JD, UK

2 Tata Steel Research Development \& Technology, Swinden Technology Centre, Moorgate, Rotherham, South Yorkshire S60 $3 \mathrm{AR}, \mathrm{UK}$
Keywords Mechanical testing $\cdot$ Microgrids $\cdot$ Strain measurement $\cdot$ High temperature $\cdot$ Damage

\section{Introduction}

Edge cracking can occur during the hot working of metals depending on steel grades, rolling pass configuration and envelope of processing conditions [1]. Such crack development at the surface of products rolled in the austenitic range can be a major issue for the steel industry in terms of production cost. Damage formation acting on evolving microstructures under complex thermo-mechanical conditions is still poorly understood and experimental insight therefore needs to be generated for the development of predictive models. Experiments conducted at high temperature are challenging mainly due to equipment reliability [2], microstructural evolution of the material [3] and oxidation issues [4] when conducted in air.

Several mechanical tests at high temperature have been developed to observe hot damage either during or after the tests. Puncreobutr et al. [5] developed a non-destructive insitu $\mathrm{x}$-ray tomography technique to observe damage development inside a free cutting steel under tensile loading at temperatures up to $1000^{\circ} \mathrm{C}$ and low strain rate. Damage development was observed at the subsurface of the free cutting steel specimen and non-metallic inclusions were identified as playing a key role for damage development at high temperature. Lin et al. [6] also carried out hot tensile testing experiments. They identified grain boundaries or inclusions as key microstructural features for damage development after sectioning the fractured specimens. Foster et al. [7] suggested that damage mechanisms generated under tensile testing alone do not provide sufficient information to understand damage formation during rolling. Therefore, substantial work [7-10] was carried out to design compressive specimen geometries that 
can generate critical stress states for the formation of damage under mechanical conditions representative of those leading to edge cracking during the hot rolling of steels. In these studies, stress triaxiality (mean stress over equivalent stress) together with equivalent strain and principal/intermediate stresses were found to be the key macro-meso mechanical variable controlling edge cracking conditions with critical triaxiality values found in the range of $0.3-0.5$ by Farrugia [11]. These studies concluded that the combination of such stress triaxiality levels and key microstructural features such as $\mathrm{MnS}$ inclusions were responsible for damage development in free-cutting steels. However, oxidation of the surface of the specimens deformed in air limited the observations and only sub-surface analysis of damage development could be carried out after sectioning the deformed specimens.

Although edge cracking has been found to be directly influenced by macroscopic stress triaxiality conditions, damage development at the scale of the microstructure is dependent on local stress/strain fields inside grains or around inclusions. Several experimental techniques have been developed to measure strain distributions at the scale of microstructures. The Digital Image Correlation (DIC) technique is increasingly used for full-field strain measurements during mechanical testing, especially with the development of computers performance, high resolution cameras, imaging technology and high acquisition rates (e.g. [12] for a comprehensive review). Applications to high temperature deformation have also been reported in the literature with studies carried out at temperatures as high as $1200{ }^{\circ} \mathrm{C}$ [13]. However, issues related to oxidation usually affect strain measurements and thus, an inert test environment is highly recommended [4]. DIC has also been used for strain measurements at the scale of microstructures with mechanical testing carried out inside a Scanning Electron Microscope (SEM) (e.g. [14-16]). Even though the technique is very useful in studying strain localisation in microstructures, most studies have been restricted to room temperature deformation. Very few applications of DIC at elevated temperature at the micro-scale can be found in the literature with one study carried out at $110{ }^{\circ} \mathrm{C}$ [17] and a more recent one at $950^{\circ} \mathrm{C}$ [18] using tensile testing. Puncreobutr et al. [5] used Digital Volume Correlation (DVC) to measure in-situ strain distributions in the volume of the deformed tensile specimen by tracking the displacement of non-metallic inclusions using X-ray tomography. Such technique is only applicable when the tested material contains traceable marks, namely non-metallic inclusions in that particular study, and the spatial resolution for strain measurements is limited by the distance between inclusions used as the gauge length for strain calculations.

The microgrid technique is another full-field strain measurement technique which has been used to quantify the deformation of materials at the scale of their microstructure [19]. Image analysis of distorted grids has been improved over the years in order to automatically compute strain distributions with higher accuracy using, for instance, Fourier transformbased methods [20,21]. The technique has also been successfully applied at temperatures as high as $1050{ }^{\circ} \mathrm{C}$ in a plane strain compression test carried out on a duplex stainless steel using a specimen geometry modified to lay microgrids at the surface of an insert welded to the rest of the specimen [22]. This experimental procedure was later further developed and applied at $850{ }^{\circ} \mathrm{C}$ in [23] and at $950{ }^{\circ} \mathrm{C}$ in [24]. However, during these tests, microgrids were engraved at the surface of the metal, through etching, and the minimum achievable pitch size was about $5 \mu \mathrm{m}$, therefore limiting the spatial resolution for local strain measurements. Moreover, the grooves generated at the surface of the metal can potentially affect subsequent microstructure evolution, including damage. Gold microgrids are therefore preferred as they are usually deposited at the surface of specimens using sputtering or evaporation [19], therefore minimising these effects. They have also been proven to survive temperatures up to $1000{ }^{\circ} \mathrm{C}$ as demonstrated in a recent study under plane strain deformation conditions [25]. In addition, the inserts used in [22-24] needed to be sealed to the rest of the specimen, through welding, to avoid oxidation of the microgrid surface. The microgrid technique is therefore not suitable for surface crack studies when tests are conducted in an unprotected environment. Soula et al. [26] successfully demonstrated the use of oxide-based microgrids to study the creep behaviour of a superalloy NR6 at the surface of a tensile specimen tested at $850{ }^{\circ} \mathrm{C}$ in the furnace of a creep machine under vacuum $\left(\sim 10^{-4} \mathrm{~Pa}\right)$. However results were, once again, limited to tensile testing conditions not representative of the large deformation experienced by steels during hot rolling.

A new experimental procedure has therefore been developed in this work to study the early stages of damage formation during hot compression testing by measuring local strain distributions at the scale of the microstructure using microgrids located on the external surface of the samples. Specimens have been specially designed to generate stress triaxiality levels, at the surface, representative of hot rolling deformation conditions leading to edge cracking. Specimens are also tested in a vacuum chamber to protect the grids from oxidation. Additionally, gold microgrids have been used to prevent any influence of the grids on microstructure evolution during high temperature deformation.

\section{Experimental Procedure}

A Fe-30wt\%Ni alloy, which does not experience any phase transformation upon cooling from temperatures typical of the hot rolling of steels, was used as a model material to study the behaviour of austenite in C-Mn steels under conditions representative of industrial hot forming operations [3]. A 
compression test sample $10 \mathrm{~mm}$ thick $\times 15 \mathrm{~mm}$ wide $\times 20 \mathrm{~mm}$ long with tapers at $30^{\circ}$ (Fig. 1(b)) was used to generate stress triaxiality levels ranging from 0.3 to 0.5 on the external surfaces of the specimen normal to the Transverse Direction (TD) and representative to those experienced at the edges of industrially hot rolled products $[9,10]$. Figure 1 (a) shows a specimen deformed in a thermo-mechanical testing machine Gleeble 3800 at Tata Steel Swinden Technology Centre with $20 \mathrm{t}$ load capacity in compression at displacement rates up to $2000 \mathrm{~mm} \cdot \mathrm{s}^{-1}$. Test specimens with thermo-couples welded onto the samples' surface can be heated up through direct resistance heating at rates up to $10,000{ }^{\circ} \mathrm{C} \cdot \mathrm{s}^{-1}$. Tests can also be conducted under vacuum with pressures down to $10^{-3} \mathrm{~Pa}$ to protect specimens from oxidation. The orientation of the specimen with respect to the compression tools used in the Gleeble machine can be seen in Fig. 1(b).

A set of gold microgrids was first deposited on one of the surfaces (normal to TD) of the specimen (Fig. 2). Gold was selected due to its good ductility in order to follow the deformation of the $\mathrm{Fe}-30 \mathrm{wt} \% \mathrm{Ni}$ alloy without undesirable cracking or detachment from the surface as well as its good chemical contrast for subsequent image analysis. The successive steps of the procedure used to deposit microgrids on the surface of the specimen are detailed below:

1. The surface of interest of the specimen is mechanically ground and polished (down to $1 \mu \mathrm{m}$ using diamond paste)

2. The microstructure of the specimen is revealed through chemical etching ( $70 \%$ Nitric acid with $30 \%$ water)

3. A thin layer of electro-sensitive polymethyl methacrylate (PMMA) resin is deposited onto the surface by centrifugation at 3000 revolutions per minute and then cured at $140{ }^{\circ} \mathrm{C}$ for $30 \mathrm{~min}$

4. PMMA resin is then irradiated using the electron beam of a SEM, with the beam externally controlled by the Nanometer Pattern Generation System (NPGS) [27] to perform microgrid printing

5. The irradiated resin can then be removed using a solution of $75 \%$ propanol and $25 \% 2$-Butanol to expose the surface of the metal along the irradiated path. A very thin layer of gold is then sputtered onto the surface of the specimen

6. The remaining resin is finally removed using ethyl acetate in an ultrasonic bath.

The various steps of the microgrid technique and final result obtained are illustrated in Fig. 2.

The microgrid pitch size can be adjusted by altering the scanning parameters and the magnification. Due to the coarse grain size of the $\mathrm{Fe}-30 \mathrm{wt} \% \mathrm{Ni}$ alloy (ranging from 100 to $350 \mu \mathrm{m}$ ), a microgrid pitch size of $20 \mu \mathrm{m}$ was selected as a compromise between adequate spatial resolution for strain measurements and reasonable printing time. A $4 \times 4 \mathrm{~mm}$ area of the microstructure was covered with such microgrids.

The compression test was conducted under vacuum in the Gleeble 3800 thermo-mechanical testing machine. The specimen was first heated up to $1000{ }^{\circ} \mathrm{C}$ in 3 min through direct resistance heating. It was then held at $1000{ }^{\circ} \mathrm{C}$ for $1 \mathrm{~min}$ in order to ensure a homogeneous temperature distribution throughout the specimen before the compression was applied. The sample was deformed at a strain rate of $1 \mathrm{~s}^{-1}$ to a true compression strain of $25 \%$. After completion of the test, the specimen was cooled down to room temperature in $45 \mathrm{~min}$ through heat conduction from the specimen to the Gleeble tools. The deformed microstructure was then observed using a SEM.

\section{Finite Element Simulation}

A finite element (FE) simulation of the deformation of the specimen was carried out using ABAQUS [28] to compute stress/strain distributions in the specimen. A 3D displacementtemperature coupled 8-noded continuum solid element (C3D8T) was used in the model. The meshed specimen was deformed by rigid tools initially set at the deformation temperature and in contact with the test-piece with a constant friction coefficient of $0.2[29,30]$. Due to symmetry for both the geometry of the specimen and applied loads, only $1 / 8$ th of the test piece geometry was simulated in the model by
Fig. 1 (a) Specimen deformed in the Gleeble machine and (b) tapered specimen before and after deformation (dimensions in $\mathrm{mm}$ )

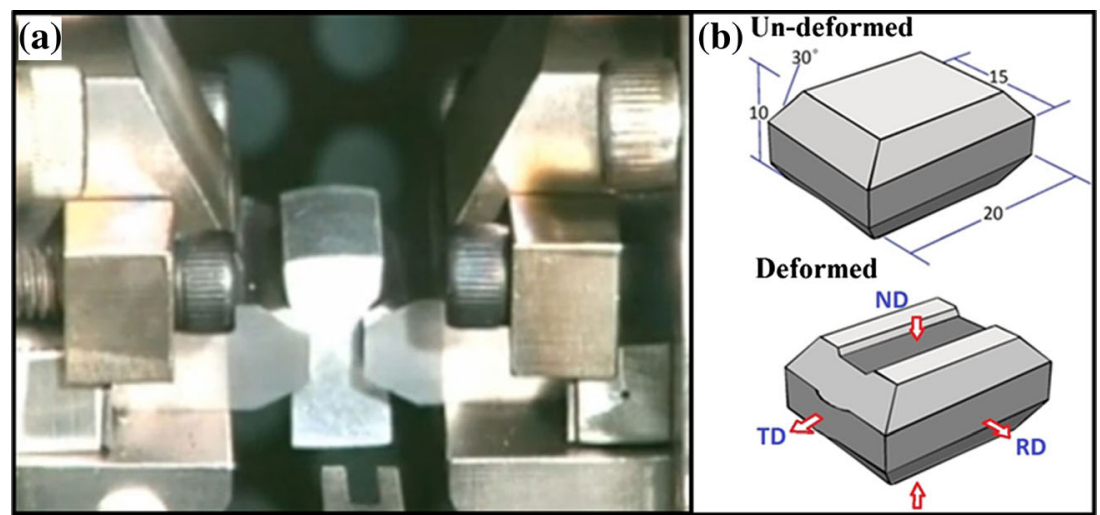




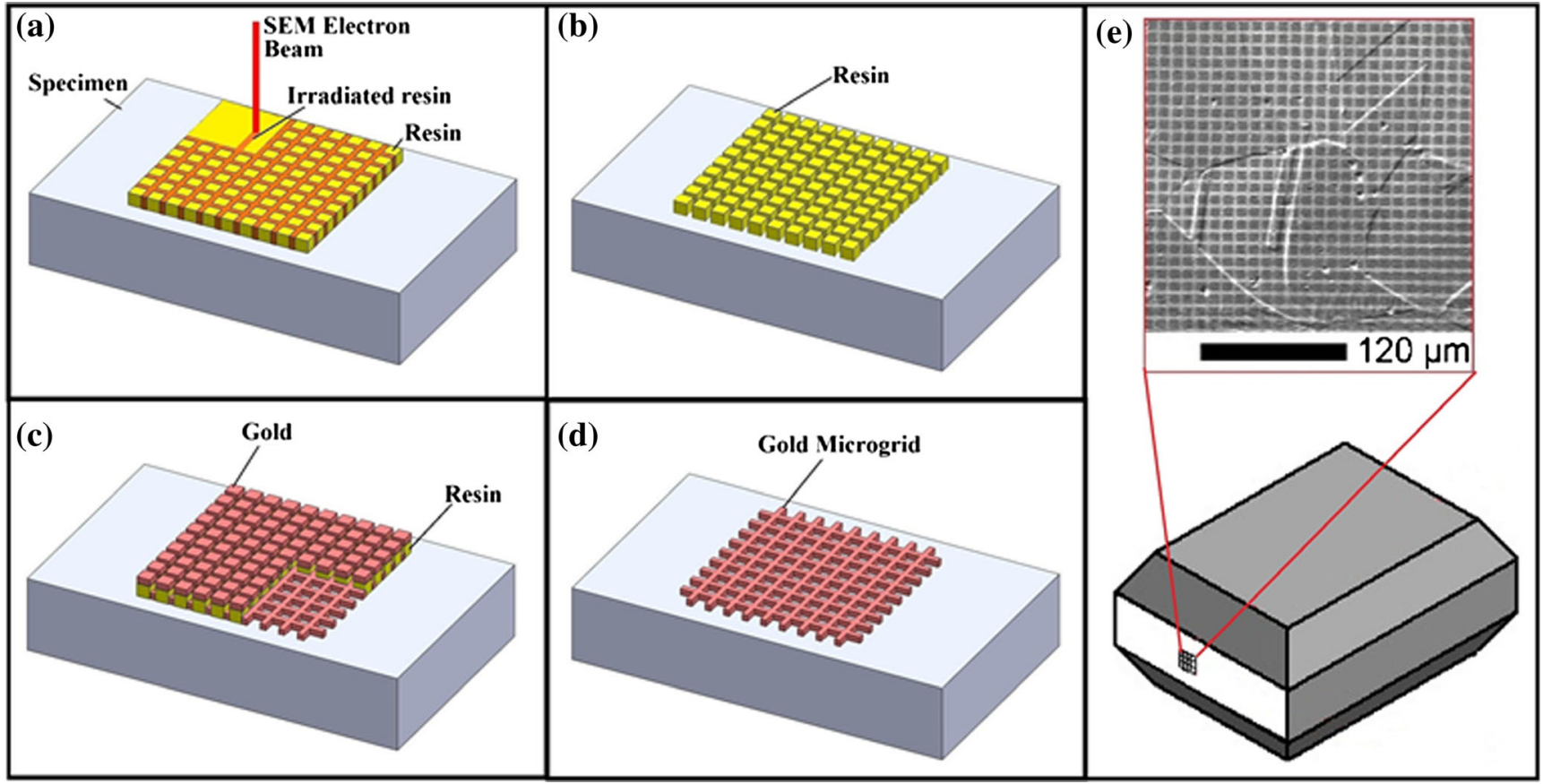

Fig. 2 (a) Deposited resin irradiated by the electron beam, (b) irradiated resin removed with solvent, (c) gold sputtered over the area, (d) removal of remaining resin to reveal the microgrid and (e) final result at the surface of the tapered specimen

applying the relevant boundary conditions on the symmetry planes in order to save computation time. Figure 3(a) shows the meshed specimen and the rigid tool before deformation. The actual compression was applied by imposing a downward vertical displacement rate, to the upper tool, matching that of the experiment in order to maintain a constant strain rate of $1 \mathrm{~s}^{-1}$. The elastic material properties reported in Table 1 along with the measured equivalent stress/equivalent plastic strain curve shown in Fig. 3(b) were introduced in the model.

\section{Results \& Analysis}

As shown in Fig. 3(b), the steady increase of flow stress with deformation indicates that no recrystallisation has taken place in the material up to $25 \%$ strain under these testing conditions. Figure 4 shows SEM images of the surface of the specimen after deformation and therefore demonstrates that the microgrid test was successful after the large deformation applied at $1000{ }^{\circ} \mathrm{C}$. Even though the test was conducted at a temperature close to the melting point of gold $\left(1064{ }^{\circ} \mathrm{C}\right)$, the microgrid is still clearly visible in the SEM image after the test. Figure 4 shows the whole microgrid area which nearly covers the entire thickness of the external surface of the specimen (normal to TD), while close-up view images show particular regions of the microgrid area. The grids are clearly visible within the grains in Fig. 4 and can therefore be analysed to produce strain maps over areas of the microstructure. Figure 4 also clearly shows the presence of damage located along several grain boundaries. This result therefore demonstrates that the experimental procedure developed in
Fig. 3 (a) Finite element model of the specimen with rigid tool and (b) Equivalent stress equivalent plastic strain curve for $\mathrm{Fe}-30 \mathrm{wt} \% \mathrm{Ni}$ deformed at $1000{ }^{\circ} \mathrm{C}$ with a strain rate of $1 \mathrm{~s}^{-1}$
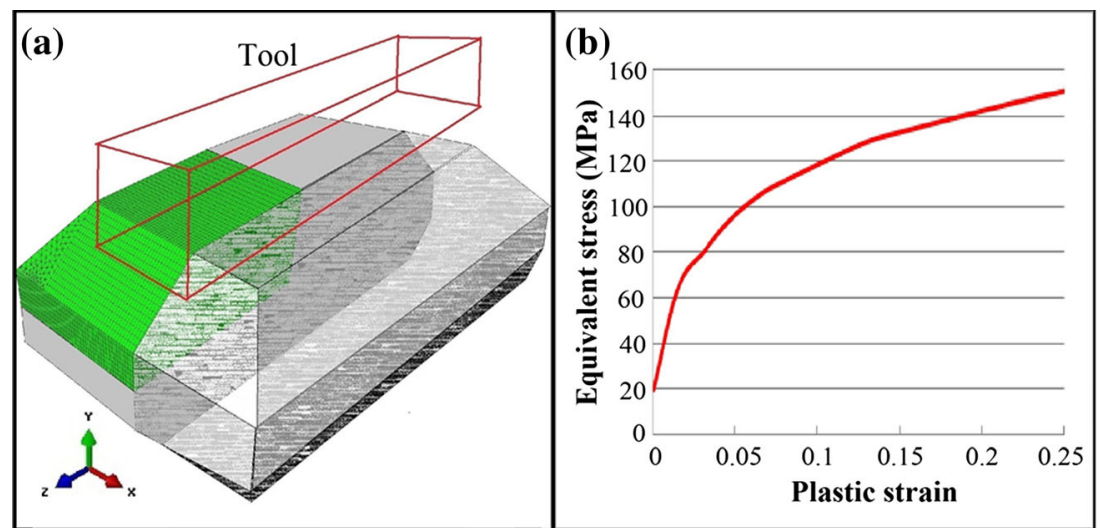
Table 1 Elastic

properties

\begin{tabular}{ll} 
Young's Modulus & $130 \mathrm{GPa}$ \\
Poisson's ratio & 0.33 \\
\hline
\end{tabular}

this work, which combines compression testing at high temperature on tapered specimens with polished external surfaces, does generate damage on the surface of the samples, which can therefore be studied in relation to both the microstructure and local deformation quantified using microgrids.

The distorted microgrids have then been analysed using a MATLAB [31] script [32] to first record grid intersection coordinates through manual mouse clicks and then to compute strain values using the procedure detailed in [33]. An automated procedure such as that reported in [21], based on continuous monitoring of the deformation of a grid in a coarse microstructure using optical CCD cameras, could not be used in the present study as only two images were recorded in the SEM, one before deformation and the other one after very large deformation of the relatively fine microstructure, following unloading of the specimen from the Gleeble machine. The large deformation experienced by the grid, along with the large variation of contrast and brightness between the two images of the un-deformed and deformed configurations, after the test carried out at high temperature, therefore make an automated procedure to process the images very challenging. For direct comparison with strain values computed by ABAQUS, logarithmic strain values have been calculated using the procedure described below.

Figure 5(a) shows a typical square generated by clicking on the line intersections located at the four corners of every microgrid element and Fig. 5(b) shows the distortion of such element after deformation. $V_{j}^{i}$ and $v_{j}^{i}$, with $\mathrm{i}, \mathrm{j}=1,2$, are the coordinates of the two sets of vectors shown in Fig. 5(a) and (b) respectively, which characterise the shape change of each microgrid element due to deformation.

The in-plane deformation gradient tensor $F$ can be computed from equation (1) using the grid intersection coordinates.

$F=\left(\begin{array}{ll}v_{1}^{i} & v_{2}^{i} \\ v_{1}^{j} & v_{2}^{j}\end{array}\right)\left(\begin{array}{ll}V_{1}^{i} & V_{2}^{i} \\ V_{1}^{j} & V_{2}^{j}\end{array}\right)^{-1}=\left(\begin{array}{ll}F_{11} & F_{12} \\ F_{21} & F_{22}\end{array}\right)$
$F$ can be decomposed into a rigid-body rotation tensor $R$ and a distortion tensor $U$ using equation (2).

$F=R \cdot U$

$U$ can be diagonalised in an orthogonal coordinate system using equation (3)

$U=Q^{t} \cdot D \cdot Q \quad(t$ stands for transposed $)$

with $D$ being the diagonal tensor and $Q$ the tensor which gives the principal directions of the distortion. The logarithmic strain tensor is then calculated using equation (4)

$\varepsilon^{\log }=Q^{t} \cdot \ln (D) \cdot Q$

Two main types of errors for the application of the microgrid technique to this work have been analysed in detail. The first type of errors relates to the inaccuracy in locating microgrid intersections during manual mouse clicking used in the MATLAB script. The close-up view in Fig. 6(a) shows that the microgrid lines are relatively irregular in shape with an approximate line width of about $3.5 \mu \mathrm{m}$. The intersection of two microgrid lines at high magnification therefore corresponds to an area whose centre cannot be determined very accurately through a mouse click, therefore leading to errors in recording coordinate values. Such error can be quantified by analysing a sufficient number of intersection points over an un-deformed microgrid area which has been analysed using the Matlab script for strain calculations. Figure 6(a) shows the un-deformed microgrid with the computed $\varepsilon_{\mathrm{yy}}$ map (y being the vertical axis corresponding to the compression direction) shown in Fig. 6(b).

The strain map, showing the distribution of non-zero strain values, can therefore be used to highlight errors in strain calculations associated with the manual clicking procedure. Results show a range of errors of about $+/-5 \%$ with a mean value of $0.19 \%$. The map also shows a linear pattern which highlights a second type of error corresponding to the drift of the SEM electron beam during irradiation. Errors due to electron beam shift $[34,35]$ are included in the overall values shown in Fig. 6(b) but they have been shown to be very small in magnitude, up to $0.4 \%$, as reported in [36], using Digital
Fig. 4 Microgrid after deformation with close-up views highlighting damage along grain boundaries

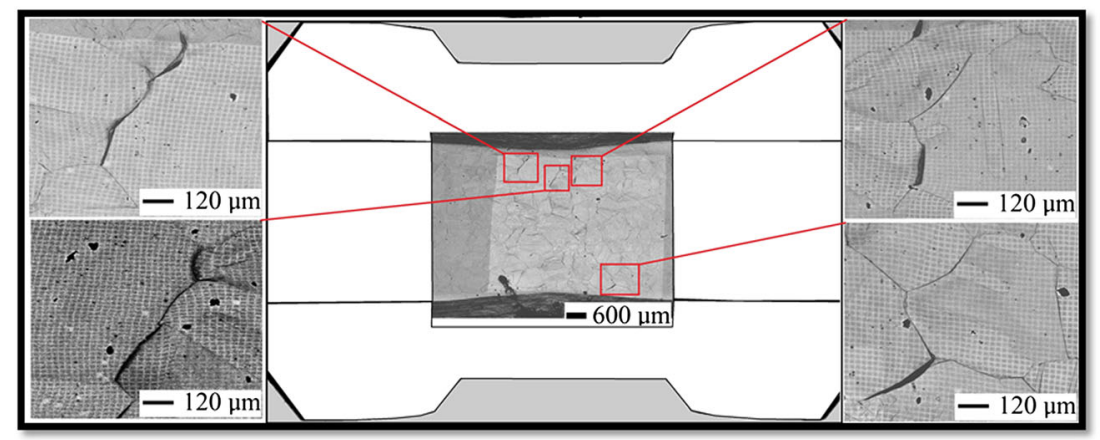




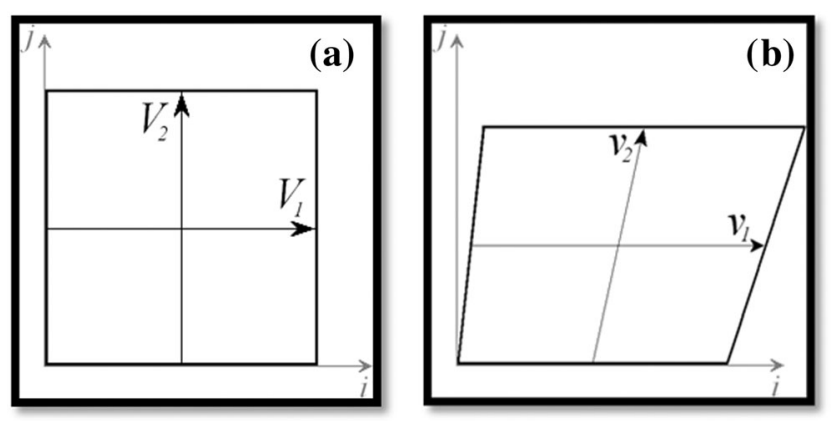

Fig. 5 (a) Undeformed configuration of a microgrid element and (b) deformed configuration

Image Correlation for strain analysis and the SEM used in this study. Despite these inaccuracies, the recorded errors remain negligible in comparison with the high strain values generated during the compression test, which will be shown later in this section.

Figure 7(a) shows the FE results in terms of $\varepsilon_{\text {yy }}$ through the thickness of the specimen with two regions $\mathrm{A}$ and $\mathrm{B}$ highlighted by rectangles over which microgrid strain measurements have been carried out. Figure 7(b) shows stress triaxiality results with values ranging from 0.3 to 0.5 through the thickness of the specimen. Region A represents a $1600 \times 1460$ micron $^{2}$ area of the microstructure shown in Fig. 7(c), and corresponds to the region where the highest $\varepsilon_{\mathrm{yy}}$ values have been computed in the FE simulation (see Fig. 7(a)). Figure 7(d) shows the corresponding $\varepsilon_{\mathrm{yy}}$ strain map after analysis of the microgrid distortion for region A. Figure 7(a) clearly shows the strain heterogeneity across the thickness due to the particular geometry of the specimen, with a maximum strain value of about $15 \%$ in compression on this particular tapered surface for $25 \%$ applied deformation. Figure 7(d) clearly shows the strain heterogeneity experienced by the material at the scale of the microstructure with strain values ranging from 0 to $75 \%$ in region $\mathrm{A}$. This heterogeneity is observed between grains and also within grains where strain values are generally higher close to grain boundaries.

The histogram shown in Fig. 7(e) quantifies the strain heterogeneity recorded over the analysed area of the microstructure with a mean strain value of $-14.2 \%$ and a standard deviation of $9.1 \%$. The histogram shows a high fraction of strain values around $-10 \%$ with high strain values ranging from -40 to $-75 \%$ contributing only to $1.2 \%$ of the overall frequency distribution. These high strain values correspond to the localisation of deformation near grain boundaries which represent a small fraction of the total microstructure area given the coarse grain size of the material. Likewise, the histogram in Fig. 7(f) quantifies the $\varepsilon_{\mathrm{xx}}$ strain heterogeneity recorded over the analysed area of the microstructure with a mean value of $15.9 \%$ and a standard deviation of $9.7 \%$. A high fraction of $\varepsilon_{\mathrm{xx}}$ values is around $25 \%$ with high strain values ranging from 40 to $60 \%$ contributing only to $4.1 \%$ of the overall frequency distribution.

Very close inspection of Fig. 7(c) reveals the presence of cracks along the grain boundaries highlighted with arrows. Cracks have been observed along several other grain boundaries in the deformed zone of the specimen, as shown in Fig. 4, with a very clear crack shown in Fig. 8(a) in an area of the microstructure corresponding to region B in Fig. 7(a). Figure 8(b) shows the strain map for this region with a lower strain range compared to region A due to its location at the transition zone between the deformed and undeformed parts of the specimen as shown in Fig. 7(a). The highest deformation in the map appears to be again located mostly along grain boundaries with strain values up to $40 \%$ in compression. It is also worth noting that strain values along the grain boundary where a crack has developed are comparatively small.

\section{Discussion}

\section{Experimental Procedure}

Results reported in the previous section have shown that the new experimental procedure developed in this work, which combines compression testing at high temperature under vacuum on tapered specimens with gold microgrids deposited on the external surface, has successfully led to damage development from the edge of the specimen where local strain distributions can be quantified. These results confirm that the
Fig. 6 (a) Un-deformed microgrid with close-up view of a typical line intersection and (b) $\varepsilon_{\text {yy }}$ error map (y: vertical axis along the compression direction)

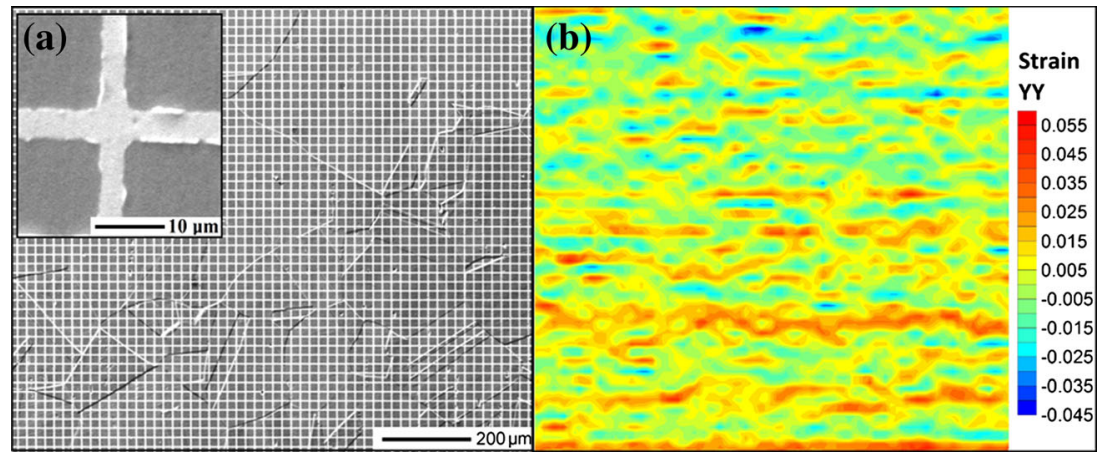


Fig. 7 (a) Simulated $\varepsilon_{\mathrm{yy}}$ with two regions highlighted $(A$ and $B),(\mathbf{b})$ simulated stress triaxiality distribution, (c) micrograph of deformed microgrids in region $\mathrm{A}$, (d) measured $\varepsilon_{y y}$ map over the deformed microstructure in Region A, (e) measured $\varepsilon_{\mathrm{yy}}$ histogram and (f) $\varepsilon_{\mathrm{xx}}$ histogram

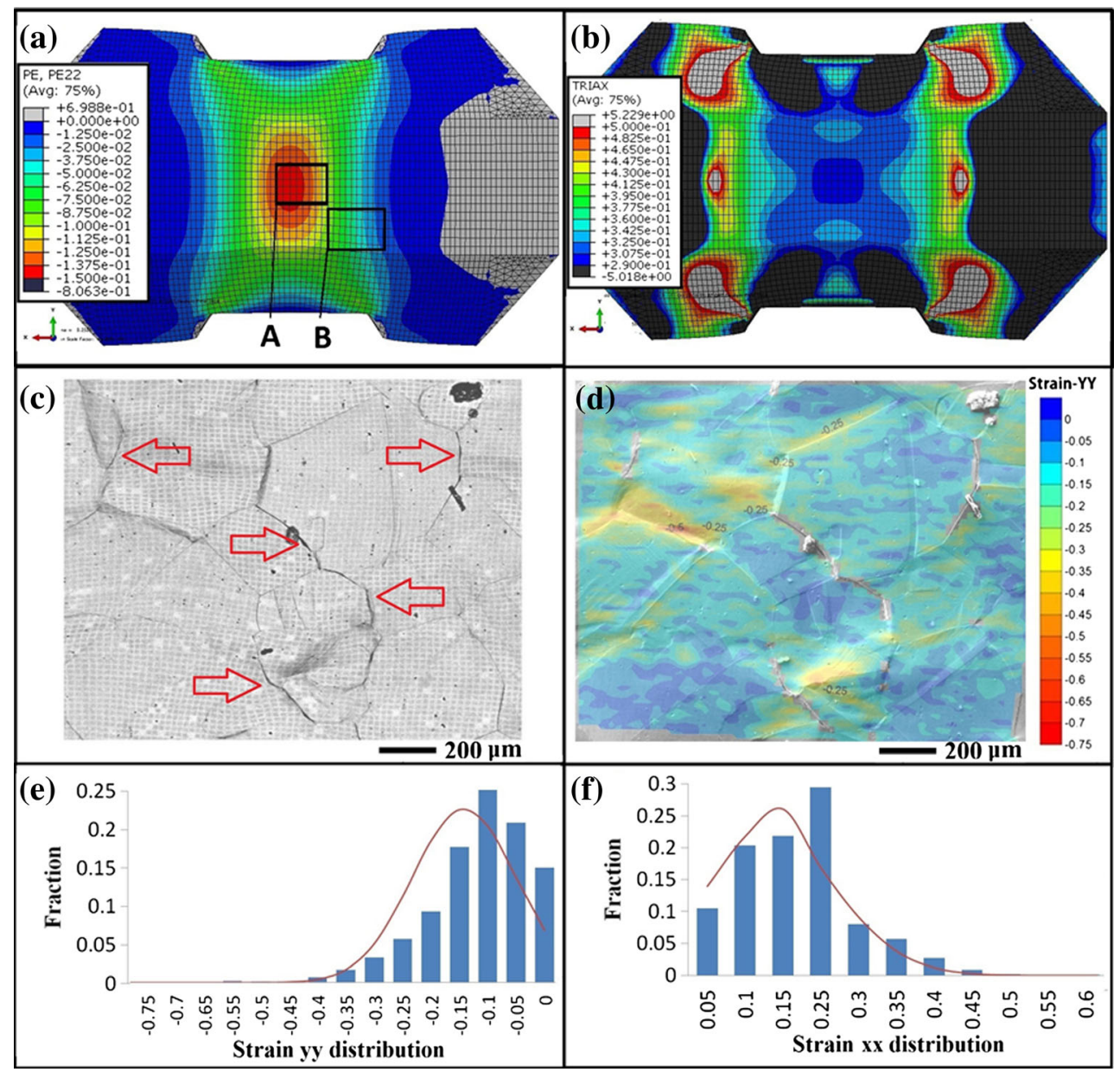

specimens' tapered geometry generate sufficient stress triaxiality levels to generate edge cracking under deformation conditions representative of hot rolling operations as previously reported in [6-10]. Figure 7(b) shows that stress triaxiality values ranging from 0.3 to 0.5 are generated at the surface of the specimen where damage appeared for $25 \%$ applied compression in $\mathrm{Fe}-30 \mathrm{wt} \% \mathrm{Ni}$. These values are therefore in line with those reported by Farrugia on free-cutting steels [11]. The model alloy used in this study, whose stress/strain curve up to $25 \%$ is comparable to that reported in [37], has allowed the microgrids to remain in the microstructure after cooling (Fig. 4), therefore enabling the characterisation of local strain distributions in relation to the early stages of damage development in hot deformed austenite. Moreover, gold microgrids do not influence damage or microstructure evolution unlike etched microgrids used in previous studies [22-24, 37]. The sharper definition of the microgrid gold lines as opposed to etched grooves also reduces the error in manually locating microgrid intersection points. The error analysis shown in Fig. 6 reports errors of about $+/-5 \%$ for $\varepsilon_{\text {yy }}$ which are
Fig. 8 (a) Micrograph of deformed microgrid in region $B$ of Fig. 7(a) and (b) corresponding $\varepsilon_{\text {yy }}$ map

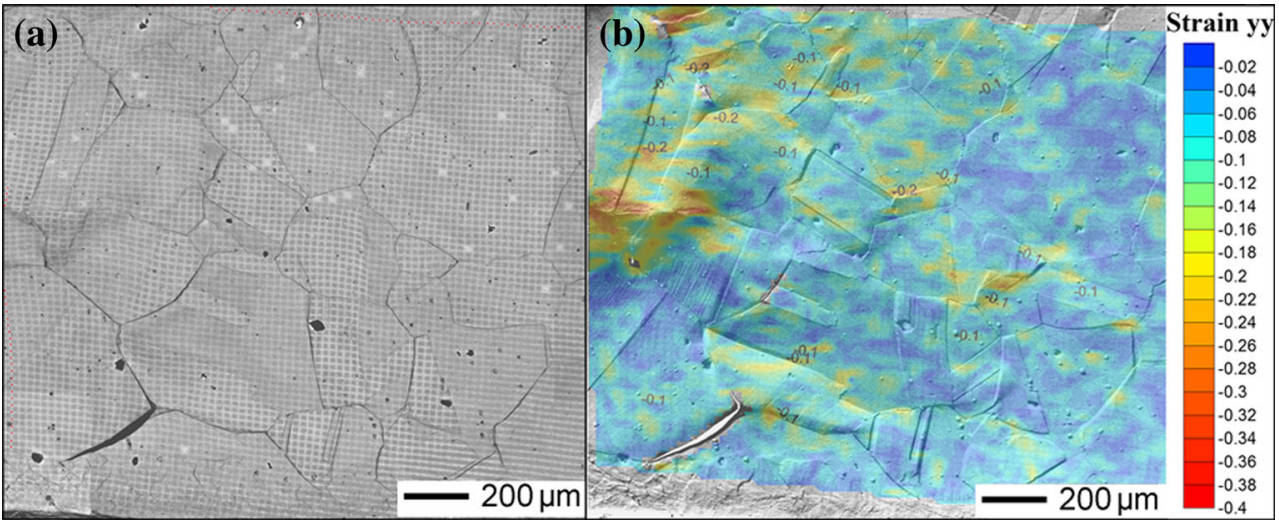


relatively small compared to the high local strain values of $75 \%$ recorded in Fig. 7(d). Accurate strain maps can therefore be generated using gold microgrids after large deformation at $1000{ }^{\circ} \mathrm{C}$ even though this temperature is close to the melting point of pure gold. Although an optimal microgrid pitch of $20 \mu \mathrm{m}$ was selected in this work due to the relatively coarse grain size of the investigated material, results obtained in this study demonstrate that a higher spatial resolution could be achieved at temperatures up to $1000^{\circ} \mathrm{C}$ by changing the scanning parameters during irradiation of the electro-sensitive resin in order to reduce the pitch size of gold microgrids. Gold is indeed commonly used for electron-beam lithography and, for instance, pitch sizes down to $40 \mathrm{~nm}$ have been reported in the literature [38] as opposed to a minimum pitch size of $5 \mu \mathrm{m}$ achieved with etched microgrids in [22-24, 37].

\section{Strain Distributions in the Microstructure of Hot Deformed Fe-30wt\%Ni}

Figure 7(d) shows the high strain heterogeneity measured in the microstructure of the $\mathrm{Fe}-30 \mathrm{wt} \% \mathrm{Ni}$ alloy at the surface of the specimen with clear localisation of the deformation along grain boundaries. Strain values up to $75 \%$ in compression are indeed recorded along one particular grain boundary while the grain interior experiences strain values below $5 \%$. Large variation in strain values are also observed between grains. Such variation within grains and between grains are likely due to local misorientations. The effect of crystallographic orientation on plastic deformation is well-known since the early work by Taylor [39] but electron-back-scattered-diffraction measurements of local orientations would need to be carried out to confirm this assumption. Strain histograms shown in Fig. 7(e) and (f) clearly confirm the heterogeneity of deformation through the spread of the distribution of strain values for the analysed microstructure. The highest strain values are clearly located along some of the grain boundaries as confirmed by the map shown in Fig. 7(d). Since the magnitude of the highest strain values differ between $\varepsilon_{\mathrm{xx}}$ and $\varepsilon_{\mathrm{yy}}$, out-of-plane deformation is therefore expected. The out-of-plane deformation can be estimated by assuming plastic incompressibility of the material which translates into the following relationship: $\varepsilon_{\mathrm{xx}}+\varepsilon_{\mathrm{yy}}+\varepsilon_{\mathrm{zz}}=0$. The out-of-plane strain component $\varepsilon_{\mathrm{zz}}$ can therefore be easily computed from the two other strain components and the corresponding strain map and histogram for region A are shown in Fig. 9.

The strain distribution in the histogram plotted in Fig. 9(b) shows a mean value of $-1.7 \%$ with a standard deviation of $10.3 \%$. This result confirms the high level of strain heterogeneity in the microstructure which is clearly seen in the strain map shown in Fig. 9(a) with values ranging between -45 and $+45 \%$. The strain map clearly shows that some of the grains move inward towards the centre of the specimen while others move outward with a mean out-of-plane strain value close to zero. As for the $\varepsilon_{\mathrm{yy}}$ map, the highest $\varepsilon_{\mathrm{zz}}$ values seem, once again, to be located along grain boundaries. It is worth pointing out that the large $\varepsilon_{z z}$ strain values shown in Fig. 9 correspond to regions affected by significant amounts of outof-plane displacement. This three-dimensional profile of the surface at these particular locations would induce additional errors for the in-plane displacement values recorded using the microgrid technique. Additional techniques such as Atomic Force Microscopy would need to be used in conjunction with the microgrid technique to quantitatively measure the out-ofplane surface profile and therefore provide more accurate inplane displacement values [40].

\section{Damage Formation at $1000{ }^{\circ} \mathrm{C}$}

Strain localisation along grain boundaries combined with high levels of stress triaxiality at the surface of the specimen, where the grids are located, can lead to the formation of cracks along grain boundaries as seen in Figs. 4 and 8. Cracks in region A of Fig. 7(a) may not have been as visible as in region B due to the comparatively lower level of stress triaxiality in that region ( 0.29 as opposed to about 0.32 ). It is worth mentioning that stress values shown in Fig. 7(b) are obtained using continuum mechanics-based calculations and therefore these computations could be refined by taking into account grain orientations in the constitutive equations of the FE model. Such simulations could also bring further insight into stress levels developed at particular grain boundaries in order to explain why
Fig. 9 (a) $\varepsilon_{z z}$ map over region A of Fig. 7(a) and (b) corresponding histogram of $\varepsilon_{\mathrm{zz}}$ distribution

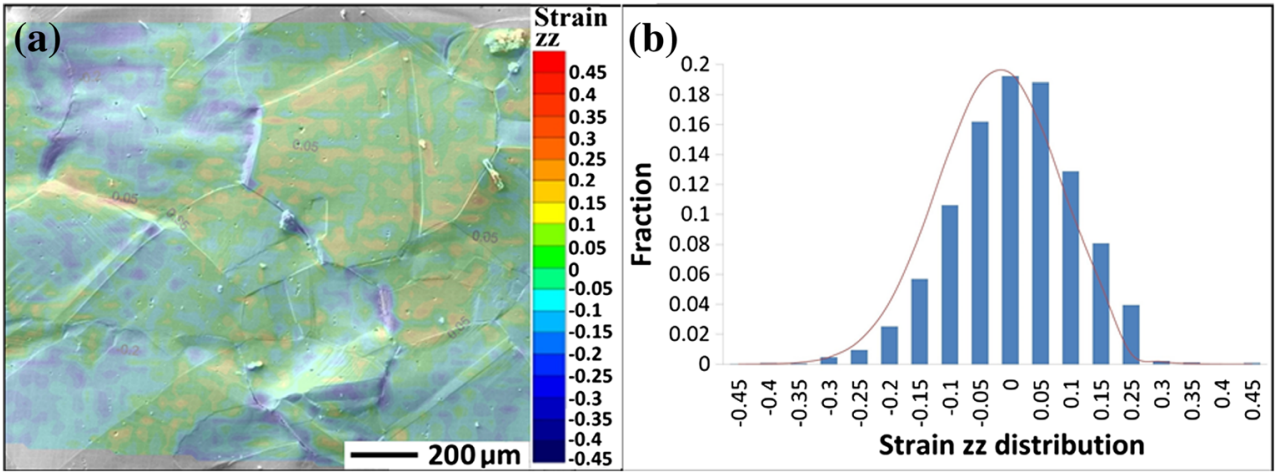


only one grain boundary located around the bottom left corner of the microstructure area in Fig. 8 has led to the formation of a crack. Although damage formation was expected after the test based on previous work by Farrugia [11], crack propagation along grain boundaries was not expected to such an extent under the deformation conditions used in this work. Liu et al. [41] who run tensile tests on free-cutting steels at $1000{ }^{\circ} \mathrm{C}$ at two very different strain rates of 0.1 and $10 \mathrm{~s}^{-1}$ indeed concluded that damage along grain boundaries is mostly observed at the lower strain rate with only very limited grain boundary damage observed at the higher strain rate. Although in this current work, compression was carried out at a uniform $1 \mathrm{~s}^{-1}$ strain rate, the local strain rate experienced by the tapered surface not in contact with the tool will be lowered, therefore explaining the extent of grain boundary damage at the surface of the specimen for this model alloy.

Results from this work have therefore shown that the early stages of damage formation as well as local strain measurements at the scale of the microstructure can be captured by the new procedure developed in this study. Experimental insight with detailed measurements of local strain distributions in the microstructure deformed at very high temperatures typical of hot forming operations for steels can therefore be used to develop physically-based models of microstructure evolution for the prediction of edge cracking in hot rolling.

\section{Conclusions}

A new experimental procedure which combines testing under vacuum and thermo-mechanical deformation conditions representative to those leading to edge cracking during the hot rolling of steels has been developed to generate damage at the surface of tapered specimens and to quantify strain distributions at the scale of the microstructure of an $\mathrm{Fe}-30 \mathrm{wt} \% \mathrm{Ni}$ alloy using microgrids. Strain maps of the local deformation of the material at the grain scale have been generated after deformation at $1000{ }^{\circ} \mathrm{C}$. Results show a high level of strain heterogeneity in the microstructure with local values as high as three times the applied strain close to grain boundaries. This localisation of deformation combined with stress trixiality levels above 0.3 can lead to the formation of cracks along some of the grain boundaries of the investigated material. These results therefore generate new insight into the conditions and mechanisms responsible for edge cracking in hot rolled steel products.

Acknowledgments The authors are grateful for the financial support provided by the Engineering and Physical Sciences Research Council (grant EP/F023464/1) and to Tata Steel for sponsoring M.F. Kiu and for providing the material and testing equipment used in this work.

Open Access This article is distributed under the terms of the Creative Commons Attribution 4.0 International License (http:// creativecommons.org/licenses/by/4.0/), which permits unrestricted use, distribution, and reproduction in any medium, provided you give appropriate credit to the original author(s) and the source, provide a link to the Creative Commons license, and indicate if changes were made.

\section{References}

1. Dieter GE (1988) Mechanical metallurgy. SI metric ed. Mc Graw Hill, London

2. Loveday MS, Mahon GJ, Roabuck B, Lacey AJ, Palmiere EJ, Sellars CM, van der Winden MR (2006) Measurement of flow stress in hot plane strain. Mater High Temp 23(2):85-118

3. Almaguer S, Sellars CM, Rainforth WM (2001) Study of the static recrystallisation of an $\mathrm{Fe}-\% 30 \mathrm{Ni}$ alloy and comparison with plain carbon steels. Int Conf Recr Gr Growth Aachen 2:831-836

4. Grant BMB, Stone HJ, Withers PJ, Preuss M (2009) Hightemperature strain field measurement using digital image correlation. J Strain Anal Eng Des 44:263-271

5. Puncreobutr C, Lee PD, Kaye M, Balint D, Farrugia DCJ, Connolley T, Lin J (2012) Quantifying damage accumulation during the hot deformation of free cutting steels using ultra-fast synchrotron tomography, IOP Conf Ser Mater Sci Eng 33. Doi:10. 1088/1757-899X/33/1/012038

6. Lin J, Liu Y, Dean TA (2005) A review on damage mechanisms, models and calibration methods under various deformation conditions. Int J Damage Mech 14:299-319

7. Foster AD, Lin J, Farrugia DCJ, Dean TA (2011) A test for evaluating the effects of stress-states on damage evolution with specific application to the hot rolling of free-cutting steels. Int J Damage Mech 20:113-129

8. Kaye M (2012) Advanced damage modelling of free machining steels. $\mathrm{PhD}$ thesis, Imperial College

9. Farrugia DCJ, Llanos J, Bianchi J, Pera J, Rodriguez-Ibabe J, Fredriksson J, Demurger J, Forestier R, Kieber B (2009) PACROLP: the prediction and avoidance of cracking in long product hot rolling, Office for Official Publications of the European Communities, 149 pp., ISBN 978-92-79-11983-5

10. Rodriguez-Ibabe JM, Revilla MC, Gonzalez N, Lardizabal PM, Farrugia DCJ, Husain Z, Claxton G, Wilcox D, Whitwood M, McGee E, Cheong B, Llanos M, Santisteban V, Bianchi JH, Macci F, Vici FD, Bouchard PO, Bernacki M, Roux E (2013) PACROLP II: the prediction and avoidance of cracking in long product hot rolling. Phase II, Office for Official Publications of the European Communities, 152 pp., ISBN 978-92-79-34585-2

11. Farrugia DCJ (2010) High temperature ductile damage during rolling of free cutting steels. Ironmak Steelmak 37(4):298-305

12. Sutton MA, Orteu JJ, Schreier HW (2009) Image correlation for shape, motion and deformation measurements. Springer, New York

13. Pan B, Wu D, Wang Z, Xia Y (2011) High-temperature digital image correlation method for full-field deformation measurement at $1200^{\circ} \mathrm{C}$. IOP Publ Meas Sci Technol 22. Doi:10.1088/09570233/22/1/015701

14. Ghadbeigi H, Pinna C, Celotto S, Yates JR (2010) Local plastic strain evolution in a high strength dual-phase steel. Mater Sci Eng A 527:5026-5032

15. Kang J, Ososkov Y, Embury JD, Wilkinson DS (2007) Digital image correlation studies for microscopic strain distribution and damage in dual phase steels. Scr Mater 56:999-1002

16. Lagattu F, Bridier F, Villechaise P, Brillaud J (2006) In-plane strain measurements on a microscopic scale by coupling digital image correlation and an in situ SEM technique. Mater Charact 56:10-18 
17. Karanjgaokar NJ, Oh CS, Chasiotis I (2011) Microscale experiments at elevated temperatures evaluated with digital image correlation. Exp Mech 51:609-618

18. Torres EA, Montoro F, Righetto RD, Ramirez AJ (2014) Development of high temperature strain instrumentation for in situ SEM evaluation of ductility dip cracking. J Microsc 254(3):157165

19. Allais L, Bornert M, Bretheau T, Caldemaison D (1994) Experimental characterization of the local strain filed in a heterogeneous elastoplastic material. Acta Metall Mater 42(11):38653880

20. Surrel Y (1994) Moire and grid methods: a signal processing approach. In: Pryputniewicz RJ, Sputnicki J (eds) Interferometry '94: photomechanics. Springer, Berlin, pp 213-220

21. Badulescu C, Grediac M, Haddadi H, Mathias JD, Balandraud X, Tran HS (2011) Applying the grid method and infrared thermography to investigate plastic deformation in aluminium multicrystal. Mech Mater 43:36-53

22. Pinna C, Beynon JH, Sellars CM, Bornert M (2000) Experimental investigation and micromechanical modelling of hot deformation of duplex stainless steels. Int Conf Math Model Metal Processing and Manuf, Canadian Inst Mining, Ottawa

23. Hernandez-Castillo LE, Beynon JH, Pinna C, van der Zwagg S (2005) Micro-scale strain distribution in hot-worked duplex stainless steel. Steel Res Int 76:137-141

24. Martin G, Caldemaison D, Bornert M, Pinna C, Bréchet Y, Véron M, Mithieux JD, Pardoen T (2013) Characterization of the high temperature strain partitioning in duplex steels. Exp Mech 53:205-215

25. Pinna C, Lan Y, Kiu MF, Efthymiadis P, Lopez-Pedrosa M, Farrugia DCJ (2015) Assessment of crystal plasticity finite element simulations of the hot deformation of metals from local strain and orientation measurements. Int J Plast 73:24-38

26. Soula A, Locq D, Boivin D, Renollet Y, Caron P, Bréchet Y (2010) Quantitative evaluation of high temperature deformation mechanisms: a specific microgrid extensometry technique coupled with EBSD analysis. J Mater Sci 45:5649-5659

27. Nanometer Pattern Generation System, User's Manual for NPGS v8 \& v9 (2004) J.C. Nabity Lithography Systems, Bozeman, Montana, USA
28. ABAQUS User's Manual, version 6.11 (2011) Dassault Systemes, Providence, RI, USA

29. Munther P, Lenard JG (1995) Tribology during hot, flat rolling of steels. CIRP Ann Manuf Technol 44(1):213-216

30. Lin JF, Huang TK, Hsu CT (1991) Evaluation of lubricants for cold strip rolling. Wear 147(1):79-91

31. MATLAB 7.10 (2010) The MathWorks, Inc., Natick, Massachusetts, USA

32. Gutierrez G (2005) Gridanalysis User's Manual. Internal report, The University of Sheffield, UK

33. Boldetti C, Pinna C, Howard IC, Gutierrez G (2005) Measurement of deformation gradient in hot rolling of AA3004. Exp Mech 45(6): 517-525

34. Sutton MA, Li N, Joy DC, Reynolds AP, Li X (2007) Scanning electron microscopy for quantitative small and large deformation measurements part I: SEM imaging at magnifications from 200 to 10,000. Exp Mech 47:775-787

35. Sutton MA, Li N, Joy DC, Reynolds AP, Li X (2007) Scanning electron microscopy for quantitative small and large deformation measurements part II: experimental validation for magnifications from 200 to 10,000. Exp Mech 47:789-804

36. Ghadbeigi H, Pinna C, Celotto S (2012) Quantitative strain analysis of the large deformation at the scale of microstructure: comparison between digital image correlation and microgrid techniques. Exp Mech 52:1483-1492

37. Hernandez-Castillo LE (2005) Determination of micro-scale strain distribution in hot-worked steel microstructures. $\mathrm{PhD}$ thesis, The University of Sheffield

38. Tobing LY, Tjahjana L, Zhang DH (2013) Direct patterning of high density sub-15 nm gold dot arrays using ultrahigh contrast electron beam lithography process on positive tone resist. IOP Publ Nanotechnol 24. Doi: 10.1088/0957-4484/24/7/075303

39. Taylor GI (1938) Plastic strain in metals. J Inst Met 62:307-324

40. Soppa E, Doumalin P, Binkele P, Wiesendanger T, Bornert M, Schmauder S (2001) Experimental and numerical characterisation of in-plane deformation in two-phase materials. Comput Mater Sci 21:261-275

41. Liu Y, Lin J, Dean TA, Farrugia DCJ (2005) A numerical and experimental study of cavitation in a hot tensile axisymmetric testpiece. J Strain Anal Eng Des 40:571-586 